however, openness and acceptance of feedback on multiple levels while focusing on learners' needs, to enhance care, can create a successful and feasible programme.

\section{P-266 COGNITIVE BEHAVIOURAL THERAPY (CBT) IN PALLIATIVE CARE: EVALUATION OF STAFF'S KNOWLEDGE, SKILL AND CONFIDENCE FOLLOWING A FOUNDATION LEVEL COURSE}

${ }^{1}$ Kathy Burn, ${ }^{2}$ Louise Lee. ${ }^{1}$ St Christopher's Hospice, London, UKi ${ }^{2}$ St Barnabas Hospice, UK

\subsection{6/bmispcare-2017-hospice.291}

Background How to utilise tools from Cognitive Behavioural Therapy (CBT) 'first-aid' in practice was taught to staff in palliative care settings. This training impacted on their knowledge and confidence when working with distress. Recent studies by Mannix et al. (2006); Anderson (2008); and Moorey et al. (2009) found that palliative care clinicians can benefit from, and effectively use the knowledge, gained from short training courses in CBT.

Aim This three-day St Christopher's, City and Guilds accredited foundation level course was delivered across two hospice sites with a total of 65 staff attending. The staff who attended represented a mix of professions, mainly experienced nursing staff but also occupational therapists, social workers, physiotherapists and counsellors. A 25 question self-reported questionnaire was developed to evaluate changes in staff confidence, knowledge, skill and practical application of psychological support and foundation level CBT. The questionnaires were completed pre- and post- the three- day course by all those attending and again at six months for one cohort.

Results The authors used the Wilcoxon Signed Paired Rank Test (Wilcoxon 1945) to analyse the statistical significance of five of the pre- and post- Visual analogue scale data. The course itself evaluated extremely positively. The results showed that statistically significant improvements at $p>0.05$ in all aspects of knowledge, skill and confidence. Further analysis after six months has also shown sustainable results.

Conclusion Staff reported great benefit from the CBT training, could use the skills and recognised the value of the training in their daily clinical practice. CBT skills can complement previous communication skills training. The training can provide staff with basic skills that can improve knowledge and confidence and can encourage them to adopt a more patient focused and goal centred approach to care.

\section{P-267 IMPLEMENTATION OF EVENING EDUCATION SEMINARS - INSPIRING THE WIDER WORKFORCE}

Helen Harland, Sarah Parnacott. Ashgate Hospicecare, Chesterfield, UK

\subsection{6/bmispcare-2017-hospice.292}

Background We identified the need to educate and up skill colleagues to improve the care of patients across all settings, with a life-limiting diagnosis in North Derbyshire. Challenges in providing education include the need to inspire the workforce, timing of education, staff release and the costs of venues and speakers.

Aims Implementation of free evening, open access education seminars for health and social care professionals across North Derbyshire.
Methods Our day hospice has capacity for 100 people and is now utilised for monthly education. We described our vision to our colleagues in primary and secondary care of providing free education and asked for their assistance to ensure a collaborative approach. We had no budget for speakers and relied on goodwill. We obtain Royal College of Physicians CPD accreditation for the lectures. We do not have to pay for accreditation as the sessions are free and simple refreshments are provided. We are registered with Eventbrite and this provides us with a register and email contact detail of all participants, minimising staff administration costs. Presentations are then emailed to attendees after the event. A certificate of attendance is rewarded on completion of a feedback questionnaire. The feedback is collated and fed back to speakers.

Results Topics presented include: management of end stage heart failure, renal disease, updates in oncological management of breast, bowel and lung cancers, symptom management, and the changing face of palliative care. Attendees include doctors, nurses from diverse care settings, AHPs, and social care staff. Attendance ranges from 43-106 personnel. In 2016-2017 we delivered education to 575 people. Feedback is excellent including staff feeling better equipped to support and manage patients.

Conclusion Evening education seminars are a successful means to educate the wider workforce. Our aim is to continue to build on our success with new and innovative topics into the future.

\section{P-268 IMPACT OF A PALLIATIVE CARE EDUCATION INITIATIVE - LOTHIAN CARE ASSISTANT DEVELOPMENT PROGRAMME}

${ }^{1,2}$ Lyndsay Cassidy, ${ }^{1,2}$ Niall Kieran. ${ }^{1}$ Marie Curie, Edinburgh, UK; ${ }^{2}$ Marie Curie, Glasgow, UK

10.1136/bmjspcare-2017-hospice.293

Introduction Social care teams are increasingly leading the delivery of care for elderly clients and their families who are living with a terminal illness. Marie Curie, in partnership with the City of Edinburgh, East Lothian Council, Midlothian Council and West Lothian Council identified the need for a bespoke education programme to be developed. The Lothian Care Assistant Development Programme encompassed a single study day, followed by an online education programme with mentorship in the participants' work setting.

Aim The overall aim of the project was to increase the knowledge and confidence of frontline staff employed by each of the four Lothian councils to care for clients living with a terminal illness.

Methods A mixed methods approach was used. A survey was completed at four time points, including an impact survey up to six months post completion of the programme. Focus groups and interviews of a sample of social care workers, mentors and managers were also completed.

Results 514 participants completed the single day programme. 71 social care workers continued on to the online module and mentorship programme. Both quantitative and qualitative data will be presented, demonstrating longer-term changes including a team approach to planning and delivering care for people living with a terminal illness. Increased knowledge and confidence from social care staff has resulted in a more person-centred approach to care, prompt recognition of uncontrolled symptoms, and policy change. 